\title{
Cultivating Grammar Knowledge of EFL Learners through Informed Peer-Dynamic Assessment
}

\section{Afshin Rezaee ${ }^{* 1}$, Siamak Rahimi ${ }^{1}$, \& Masomeh Mehrabi ${ }^{1}$}

\section{* Correspondence: afshinrezaee50@gmail.com \\ 1. Language Department, Ayatollah \\ Borujerdi University, Iran}

Received: 7 June 2019

Revision: 12 August 2019

Accepted: 22 August 2019

Published online: 20 September 2019

\begin{abstract}
The present study set out to investigate if informed Peer Dynamic Assessment (PDA), as an alternative to Dynamic Assessment (DA), can cultivate grammar learning of Iranian intermediate EFL learners. To accomplish the objectives, two intact classes including 15 female students, aged from 16 to 20 , were selected and randomly assigned into two groups, namely, experimental and control at Iran Language Institute in Khorram Abad City, Lorestan Province. The experimental group was trained on principles and procedures of PDA during two sessions to make sure that the participants know how to provide their peers with graduated feedback appropriately. Next, they were teamed up in groups of three in order to work on a number of grammatical structures embedded in their course book for ten sessions. In contrast, the control group worked on the same grammatical structures according to traditional approaches wherein feedback was given unsystematically by the teacher. Furthermore, three parallel grammar tests, designed and developed by a panel of well-experienced EFL teachers, were administered as pre-test, post-test, and delayed post-test to measure the participants' grammar knowledge prior and after the instructions. The collected data were analyzed using ANCOVA test. Results revealed that there was a statistically significant difference between the experimental and control groups in terms of gain scores on the post-test. In addition, the findings indicated that the experimental group outperformed the control group on the delayed post-test. In light with the findings, some pedagogical implications were presented for EFL teachers and learners.
\end{abstract}

Keywords: dynamic assessment, peer dynamic assessment, grammar learning, EFL learners 


\section{Introduction}

After a long period of dominance of the dualistic perspective toward teaching and assessment, in the 1960s and early1970s, Dynamic Assessment (DA), was introduced by Luria (1961) in contrast to static assessment. In static or so-called non-DA, when students are assessed, great efforts are made to assure that assessment procedures are the same for everyone, and any interaction or intervention during the assessment itself is viewed as unfair or even cheating. From the perspective of static assessment's advocates, instruction and assessment are considered as two enterprises which rarely feed into each other (Khoshsima \& Rezaee, 2016). Often times the testers wait for the instruction to be completed, and then they start to measure what learners have acquired from the offered instruction. In fact, proponents of this paradigm, consider any intervention in the assessment procedure harmful to test reliability (McNamara, 2001).

Research findings in the scope of DA indicate that mediation during assessment not only helps students to perform better on individual tests, but it also helps them to go beyond their current level of abilities (Lantolf \& Poehner, 2014). In fact, assessment sessions are considered as opportunities to improve abilities that have not been fully developed. DA proponents, in contrast to non-DA, argue that important information about students' ability can be only obtained by offering appropriate scaffold and assistance during the assessment rather than isolated performance independent of others. As Lantolf and Poehner (2004) pointed out, not only can DA provide a different picture of an individual's abilities, it can actually help him/her to develop those developing abilities by graduated and contingent mediation, while engaged in the assessment tasks. In Poehner's (2009) exact words, "the more familiar assessment model in which teachers observe student performance is replaced by one in which teachers and students jointly carry out activities, with teachers intervening as necessary to help learners stretch beyond their current capabilities" (p.471). This mutual engagement functions simultaneously as instruction and assessment because teachers not only discover where and when learners encounter problems but also provide support to overcome them.

\section{Literature Review}

Dynamic assessment (DA) compared to traditional/static assessment has been developed as a significant trend for applied linguists and language practitioners during the last few decades. In this new approach to assessment, individual differences among L2 learners and their implications receive massive attention. In this approach, as Lantolf and Thorn (2006) put it, testing comprises intervention and mediation within the procedure of assessment by teachers or more knowledgeable peers. According to Poehner (2008), mediation is one of the key features of DA that can be defined simply as the assistance provided, usually by skilled persons, to learner/test taker before or during the learning or assessment in order to understand his/her potential for learning on one hand, and to help them develop their cognitive abilities, on the other hand. However, it is worth mentioning that the offered mediation should be adapted to the current level of individual's abilities and must aim at promoting learner development (Lidz \& Gindis, 2003).

To look at the issue from another perspective, DA differs from traditional assessment in terms of theoretical foundations, assessment procedures, and interpretation of results (Carney \& Cioffi, 1992). In DA, as a process-oriented approach, the focus is devoted to the direct relationship between instruction and assessment, that is; instruction and assessment are considered interrelated and concurrent (Embreston, 2004). To put it in historical terms, DA has been introduced to and employed in educational settings including language teaching classes around the globe to overcome the demerits of static testing. Research findings show that mediation given during testing not only can assist the students to do better on tests, but they also help them to move beyond their current level of abilities (van Compernella \& Zahng, 2013). It aids students revise and implement the abilities that have not been completely developed. In the literature on DA, there have been a number of different alternative approaches toward the application of DA in educational settings like Group-Dynamic Assessment (G-DA), Computerized-Dynamic Assessment (C-DA), and Peer-DA.

Theoretically speaking, DA is founded basically in Vygotsky's (1978) conceptualization of Zone of Proximal Development (ZPD). In Vygotsky's (1978) terms, ZPD can be defined as the potential distance or range between what learners can do independently and what he/she does with assistance. This assistance should be introduced and presented to the learner gradually and can range from the most implicit to the most explicit standardized prompts. Vygotsky believes that for a human being, unlike animals, to develop his cognition and knowledge of the world, they should interact with the environment in a mediated rather than directed way by using and employing social and cultural tools and symbols like language. While interacting with world, social integrations play a significant role in the development of a persons' cognition since cognitive development emerges through interaction and engagement with others (Poehner \& Lantolf, 2005). To put it differently, for Vygotsky, the human mind is not located in his/her head 
but consists of collaboration and interaction with others and utilizing the physical and symbolic tools and artifacts to manipulate our general surroundings. Vygotsky's Sociocultural theory (SCT) of mind holds that cognitive development occurs at two levels: interpsychological and intrapsychological.

Every function in the child cultural development appears twice: first, on the social level, and later on the individual level; first, between people (interpsychotical) and then inside the child (intrapsychoogical). This applies equally to voluntary attention, to logical memory, and to the formation of concepts. All the higher functions originate as actual relationships between individuals (Vygostky, 1978).

According to Aljaafreh and Lantolf (1994), the transition from inter- psychological to intra-psychological functioning is emerged through a dynamic process of offering mediation. To put it briefly, mediation can be regarded as the process through which humans deploy cultural constructs artifacts, concepts, and activities to regulate (i.e., gain voluntary control over and transform) the material world or their own and each other's social and mental activities (Lantolf \& Thorn, 2006). Mediation and prompts can be given to the learners either externally when a person needs help to perform some function or internally, as when the exploitation of personal resources is enough to perform a function. The external mediation can be organized in either interventionist or interactionist. When the mediator draws on the same assisting prompts for all individuals, it is called interventionist approach while in interactionist approach the mediator attunes the mediation to the individual's needs (Davin, 2013).

Concerning the dependent variable, namely grammar learning, as Freeman (2014) and Lightbown and Spada (2013) pointed out, there is a general consensus that having a basic knowledge of grammatical structures of second language seems necessary to use language both accurately and fluently in actual situations. However, in the literature of second language teaching, a comprehensive consensus over the optimal approach for teaching grammar has not been obtained. For instance, some scholars like Krashen (1982) emphasized the implicit teaching of grammar. On the other hand, others such as Ellis (2008) pays much attention to explicit teaching. Furthermore, while the major part of the available literature on language learning in general and grammar learning in particular has zoomed on the role of instructions, the function of assessment has been to some extent overlooked (Rezaee, Miri, \& Razavipour, 2015). Therefore, implementing DA where instruction and assessment are integrated and are considered as a unified enterprise can be deemed quite necessary. In this regard, DA and its alternatives, including Group-Dynamic Assessment (G-DA), Computerized Dynamic Assessment (CDA), and Peer DA have been claimed to have the potential to provide a much better situation for learning language skills and components (Lantolf \& Poehner, 2014; Poehner \& Lantolf, 2013).

Here, to get a better understanding about the issue, some empirical studies will be critically reviewed. Kozulin and Garb (2002) designed and developed an interventionist approach to DA that they were using with adult immigrants English learners. In general, the findings revealed that the employed procedure was both feasible and effective in getting information on learning potential of the participants. It was approved that students with a similar performance level demonstrated different, and in some cases dramatically different abilities to learn and use new text comprehension strategies.

In a seminal study, Poehner (2009) examined the applicability of Group-Dynamic Assessment (G-DA) as an alternative approach to one-to-one DA. He analyzed a number of selected episodes taken from a teacher's interaction with the class of fourth-grade students aged 9-10. The results of the analyses indicated that G-DA's contribution to L2 education is so effective that it can render classroom interaction more systematic and more attuned to learners' emergent abilities. In addition, it was found that, in the G-DA's procedures, the teacher could proceed from a developmental perspective that informs her about the moment-to-moment interpretations of learners' needs and helps her decide how to best provide feedback.

One of the seminal studies of van Compernolle and Williams (2013) was on G-DA in the L2 language classroom. They explored the notion of active reception during small-group collaborative interaction in the foreign language classroom. The focus was on the embodied participation of a secondary (non-speaking) interactant, Dian, their subject. They argue that within small-group work a ZPD can be formed in which individuals pool their collective resources to push the group's developing understanding of a problem or task while at the same time potentially benefiting individual's members of group. The result indicates that active reception and participation have the potential to help learners develops how to improve their performance and the group's ZPD can be engaged to assist all of members. It should be noted that the results were in harmony with Poehner's work (2009). 
In the Iranian context, Birjandi, Estaji, and Deyhim (2013) carried out a study to explore the application possibility and development of DA procedures in proceeding comprehension and metacognative awareness reading strategy. In fact, the effectiveness of DA compared with non-DA was examined and it was found that mediation had a significant effect on the performance of the participants in the experimental group. The results proposed that DA can be considered as an effective means of recognizing the learners' potential abilities and giving them a helping hand to control reading comprehension difficulties.

Rezaee, Miri, and Razavipour (2015) carried out a study on the application of Peer-DA to teaching reading comprehension and vocabulary. They selected 21 female high school students aged 16-18. Based on the gathered results, the researchers concluded that the students' vocabulary and reading comprehension improved significantly from pre-test to post-test. The audio-recorded dialogues between groups were transcribed and microgenitically analyzed to open a new window to the processes undertaken in DA sessions.

Last but not least, Tabatabee, Alidoust, and Sarkeshikian (2018) explored the effect of interventionist and cumulative group dynamic assessments on EFL learners' writing accuracy. A total of 75 female high school students studying in the third grade were selected and assigned into three groups, including interventionist dynamic assessment, cumulative group dynamic assessment, and static assessment. The researchers used some wordless picture-sequence prompts for narrative writings in the pre-test, treatment, and post-test sessions. After the pre-test, only the experimental groups received mediational support. The results revealed that cumulative group dynamic assessment is more effective to develop writing accuracy in Iranian high school students compared to the other two treatments.

\subsection{Problem Statement}

It is a fact that grammar knowledge is an essential requisite for learners to be able to perform well in language skills of English (Ellis, 2008; Freeman, 2014). However, there has been a lack of a comprehensive consensus over the optimal approach for teaching grammar in SLA literature (Lightbown \& Spada, 2013). Furthermore, the main body of the literature available on grammar component has mainly focused on teaching while the crucial role of assessment in building EFL learners' competence has been noticeably underestimated if not totally ignored (Rezaee, Miri \& Razavipour, 2015). Therefore, implementing alternative approaches which integrate teaching and assessment of grammar seems quite necessary. It has been demonstrated that DA enjoys the required features to emerge simultaneously teaching and assessment (Pohener, 2008). However, as explained above, a criticism leveled at applying one-to-one DA in classroom context is that the class time is not enough for providing mediation to all learners; thus, just a few of students are cognitively engaged in and benefit from the teachers' mediation while other students' engagement remains a matter of doubt and question (Davine, 2011; Davin \& Donato, 2013). In order to solve this practicality drawback of one-to-one DA in large classes, especially in the Iranian setting where public classes are usually crowded, PDA can be introduced and used (Rezaee, Miri, \& Razavipour, 2015).

Although the advent of DA dated back to some decades ago, it is still not widely practiced around the world (Lantolf \& Pohner, 2014). Furthermore, though it seems that the theoretical attractiveness of DA opens its way into large classes, EFL teachers have not welcomed it into their real classrooms yet. Parts of this hesitation and reservation of EFL teachers stem from scarcity of research findings, and, most especially, concerning grammar, for our knowledge, still no study has been done in the EFL context of Iran. To fill up the lacuna, therefore, the present study makes attempts to shed light on the efficiency of informed PDA to cultivate grammar learning in the Iranian high school students.

\subsection{Research Questions}

To get the objectives of the current study, the following research questions were investigated:

1. Does informed Peer-Dynamic Assessment lead to any significant improvement in the grammar learning of intermediate EFL learners?

2. Does informed Peer-Dynamic Assessment lead to any significant improvement in intermediate EFL learners' longterm retention of grammar learning?

\subsection{Research Hypotheses}

In line with the research questions, the following null hypotheses were put forward and investigated. 
$\mathrm{H0}_{1}$ : Informed Peer-Dynamic Assessment does not lead to any significant improvement in the grammar learning of intermediate EFL learners.

$\mathrm{HO}_{2}$ : Informed Peer-Dynamic Assessment does not lead to any significant improvement in intermediate EFL learners' long-term retention of grammar learning.

\section{Methodology}

\subsection{Research Design}

To get the objectives of the current study, a quantitative approach was employed. Due to the fact that the data were collected from two intact classes, namely experimental and control, as well as, the participants were not fully homogenized prior running the main study, this research is considered quasi-experimental. In fact, this research aimed at investigating the impact of informed peer-DA on Iranian EFL learners' grammar learning using a pre-test, treatment, and post-test quasi-experimental design.

\subsection{Setting and Participants}

Two intact classes consisting of $15 \mathrm{~L} 2$ learners in each class were selected and randomly assigned into experimental group and control group to participate in the study. In fact, this research was conducted in Iran Language Institute (ILI) in Khoram Abad City, Iran. The participants were all female, whose age ranged from 16 to 20. They were learning English as a foreign language by attending English classes three times a week where they practiced language skills (listening, speaking, reading, and writing) and worked on language components (grammar, vocabulary, pronunciation, and spelling). Another prevailing feature embodied in the participants' classes was that language teachers tried to mainly manage their classes in target language (English) and adopt a communicative approach. It is worth noting that in order to allow students to maximally benefit from collaboration and interaction with more capable peers, an attempt was made to include low, average, and high level of proficiency in each of the Peer-DA groups. Finally, it should be noted that based on the ILI evaluation procedures, it was made sure that the students were at intermediate level.

\subsection{Instruments}

In order to collect the required data, three parallel teacher-made grammar knowledge tests were designed and developed by a panel of well-experienced EFL teachers. The panel members, who were three EFL teachers, were invited based on their years of experience in English teaching and familiarity with the students' course book. The tests contained the grammatical constructions included in each lesson of the students' textbook. The textbook' lessons included a range of grammatical structures such as passive and active voice, direct and indirect speech, two-word verbs, be going to, present perfect tense, relative clauses, and gerund structures. Each of the tests comprised 10 multiple-choice items and 10 grammaticality judgment items including all grammar points of the students' course book in order to gauge grammatical knowledge of the students before and after the instructions. In order to determine validity and reliability of the tests, they were piloted on a group of 15 students with the same characteristics as the participants in the main study. According to the participants' responses in pilot study, the reliability of the designed tests was calculated through Cronbach $\alpha(0.78,0.71$, and 0.68$)$. To examine the validity of the teacher-made grammar tests, experts' judgment strategy was employed. In other words, the tests were given to three EFL teachers to examine whether the teacher-made grammar tests had a high level of face and content validity. All the EFL teachers approved that the grammar tests had a high level of validity and they could be used for the purposes of this study.

\subsection{Data Collection Procedures}

In order to conduct the present study, the following steps were taken in turn. Before running the main study, a pilot study was done by the researchers to discover factors that can probably influence the main study. The pilot study, as mentioned before, was carried out with language learners who had the same characteristics as the participants in the main study. Based on the students' responses, the items of the tests were modified, revised, and omitted. The next step included a pre-test administration. Before starting the mediational sessions, one of the designed teacher-made grammar tests, as a pre-test, was administered at one setting to measure students' initial knowledge of the target grammatical structures in both the experimental and control group. In the treatment phase, for the peer-DA group, the learners were divided into five three-member groups. At the onset of mediation phase, in order to further prepare the participants to carry out Peer-DA in the classroom, two tutorial sessions were held by the researchers during which they instructed the participants the required principles and procedures of SCT, DA, and Peer-DA to run the study. The researchers 
and students discussed in detail the way through which the groups would be interacting with each other based on PeerDA procedures in a cooperative setting. An attempt was made to focus the students' attention on the occasions where the students were expected to follow the principles of Peer-DA to give feedback appropriately. In fact, the researchers endeavored to assist the L2 learners know how to provide feedback which was graduated, dialogic, and contingent.

After the two preparatory sessions, the intervention was conducted for 10 sessions. Each session lasted one hour to work on the grammar points embedded in the students' course book. More precisely, at the outset of each session, the teacher provided a briefing on the grammatical structures and directed the students' attention to different aspects of the intended grammar points. Afterwards, the students were asked to team up and to work on the structures. The students collaboratively attempted to get full control over the structures by receiving mediations provided by their partners. When an error occurred, the participants tried to scaffold each other. They, precisely speaking, used Davin and Donato's (2013) framework (Table 1) in an interactionist way; that is, "by providing contingent and graduated support, called mediation, in the form of question, hints, and prompts" (Aljaaffreh \& Lantolf, 1994, p.6). The participants employed the five following prompts in the given order:

Table 1. Mediations/prompts provided by teacher (Adopted from Davin \& Donato, 2013)

\begin{tabular}{ll}
\hline Level of Explicitness & \multicolumn{1}{c}{ Mediation/Prompt } \\
\hline Prompt 1 & Pause with skeptical look \\
Prompt 2 & Repetition of entire phrase by teacher \\
Prompt 3 & Repetition of specific site of error \\
Prompt 4 & Forced choice option (i.e., when or where?) \\
Prompt 5 & Correct response and explanation provided \\
\hline
\end{tabular}

The process of providing graduated feedback, from implicit to explicit, continued until all problems with different aspects of the grammatical structures were rectified by the L2 learners. In line with Davin (2013), the students were allowed to use both L1 and L2 to avoid misunderstanding.

In the control group or more precisely non-Peer-DA group, the participants were taught according to the traditional teaching approaches where the students' errors were corrected directly. In other words, first, the teacher in the control group offered an explanation about each grammar point and, then, provided some examples. After following the same procedures for 10 sessions for the two groups, a post-test was administered to observe how the participants had benefited from the types of instructions, employing Peer-DA and non-Peer-DA approaches. Finally, in order to see whether there was a significant difference between the two groups in long-term retention of the instructed grammatical structures, a delayed post-test was administered four weeks later.

\subsection{Data Analysis}

In order to respond to the research questions of the present study, using SPSS version 22, both descriptive and inferential statistics were used. Besides measures of central tendency and those of variability, a test of Analysis of Covariance (ANCOVA) was run to identify the differences between the two groups in terms of their gain scores across the pre-test, immediate post-test, and delayed post-test administrations.

\section{Results}

Before delving into the findings of the first research question, it seems necessary to find out whether the obtained pretest scores for the two groups were different or not. Descriptive statistics, as reported in Table 2, indicated that there existed a marginal difference between scores on the pre-test for both groups Peer-DA $(\mathrm{M}=4.07)$ and $(\mathrm{SD}=1.83)$; and non-Peer-DA $(\mathrm{M}=4.20)$ and $(\mathrm{SD}=1.42)$. 
Table 2. Descriptive statistics for Peer-DA and Non-Peer-DA groups on the pre-test

\begin{tabular}{|c|c|c|c|c|c|}
\hline \multicolumn{6}{|c|}{ Group Statistics } \\
\hline & Instruction & $\mathrm{N}$ & Mean & Std. Deviation & Std. Error Mean \\
\hline \multirow[t]{2}{*}{ Pre-test } & Peer-DA & 15 & 4.07 & 1.831 & .473 \\
\hline & Non-Peer-DA & 15 & 4.20 & 1.424 & .368 \\
\hline
\end{tabular}

Nevertheless, to check whether there was a statistically significant between the groups' mean scores, an independent sample t-test was run.

Table 3. Independent Sample T-test of the pre-test

\begin{tabular}{|c|c|c|c|c|c|c|c|c|c|c|}
\hline & & \multicolumn{2}{|c|}{$\begin{array}{l}\text { Levene's Test } \\
\text { for Equality of } \\
\text { Variances }\end{array}$} & \multicolumn{7}{|c|}{ t-test for Equality of Means } \\
\hline & & \multirow[t]{2}{*}{$\mathrm{F}$} & \multirow[t]{2}{*}{ Sig. } & \multirow[t]{2}{*}{$\mathrm{t}$} & \multirow[t]{2}{*}{ df } & \multirow[t]{2}{*}{$\begin{array}{l}\text { Sig. (2- } \\
\text { tailed) }\end{array}$} & \multirow[t]{2}{*}{$\begin{array}{l}\text { Mean } \\
\text { Difference }\end{array}$} & \multirow[t]{2}{*}{$\begin{array}{l}\text { Std. Error } \\
\text { Difference }\end{array}$} & \multicolumn{2}{|c|}{$\begin{array}{l}95 \% \text { Confidence } \\
\text { Interval of the } \\
\text { Difference }\end{array}$} \\
\hline & & & & & & & & & Lower & Upper \\
\hline \multirow[t]{2}{*}{$\begin{array}{l}\text { Pre- } \\
\text { test }\end{array}$} & $\begin{array}{l}\text { Equal } \\
\text { variances } \\
\text { assumed }\end{array}$ & 1.557 & .222 & $\begin{array}{l}- \\
.223\end{array}$ & 28 & .825 & -.133 & .599 & -1.360 & 1.094 \\
\hline & $\begin{array}{l}\text { Equal } \\
\text { variances not } \\
\text { assumed }\end{array}$ & & &.-223 & $\begin{array}{l}26.40 \\
2\end{array}$ & .826 & -.133 & .599 & -1.364 & 1.097 \\
\hline
\end{tabular}

As portrayed in Table 3, Leven's test indicated that the variances were equal; that is, the sig value was larger than the critical value (0.05), so the first row of the table was taken into account, showing that the difference between the means for both groups was not statistically significant, $(\mathrm{t}(28)=-.22, \mathrm{p}=0.82$ (two-tailed)).

The first research question intended to explore whether there was a statistically significant difference between the immediate post-test scores as a result of two types of instruction, Peer-DA and non-Peer-DA, while the effect of the pre-test (Covariate) was controlled. To this aim, a one-way ANCOVA was run. Initially, the assumptions for conducting this parametric data analysis procedure were examined. That is, the normality, linearity, homogeneity of the variances, and homogeneity of regression slopes were explored. Concerning the first assumption, the results revealed that the scores were roughly normally distributed.

Furthermore, Leven's test of the equality of the variances indicated that the variability of scores for each of the groups was similar. As seen in Table 4, the sig level (0.16) was larger than alpha level (0.05), which means that the assumption of the equality of the variance has been satisfied. Thus, due to the normal distribution of the scores, homogeneity of the variances, use of interval scale, and independence of observations, a parametric data analysis technique, one-way ANCOVA, was applied. 
Table 4. Leven's test of equality of error variance

Dependent Variable: Immediate Post-test

$\begin{array}{llll}\text { F } & \text { df1 } & \text { df2 } & \text { Sig. } \\ 2.026 & 1 & 28 & .166\end{array}$

Tests the null hypothesis that the error variance of the dependent variable is equal across groups.

a. Design: Intercept + pre-test + Instruction

Regarding linearity, the findings showed that the scores were distributed in a roughly linear manner, so it was concluded that the linearity assumption was not violated. Moreover, the dependent variable (post-test scores) and the covariate (pre-test scores) had the same slopes; for this reason, it can be claimed that another assumption of ANCOVA, homogeneity of regression slopes, was maintained. Having examined the required assumptions for parametric tests, the descriptive statistics results, as reported in Table 5, indicate that there was a noticeable difference between the means of the immediate post-test scores of the groups Peer-DA (M=11.84, SD,=2.23); non-Peer-DA $(M=6.13$, SD= 1.64).

Table 5. Descriptive statistic for comparing the Peer-DA and Non-Peer-DA on the immediate post-test

\begin{tabular}{llll}
\hline Dependent Variable: Immediate Post-test & & \\
\hline Instruction & Mean & Std. Deviation & $\mathrm{N}$ \\
Peer-DA & 11.47 & 2.232 & 15 \\
Non-Peer-DA & 6.13 & 1.642 & 15 \\
Total & 8.80 & 3.326 & 30
\end{tabular}

Thus, to see whether the difference was significant and how much of the difference was due to the effect of independent variable, instruction type, one-way ANCOVA test was run.

Table 6. One-way ANCOVA for comparing the Peer-DA and Non-Peer-DA on the immediate post-test

\begin{tabular}{|c|c|c|c|c|c|c|c|}
\hline \multicolumn{8}{|c|}{ Tests of Between-Subjects Effects } \\
\hline \multicolumn{8}{|c|}{ Dependent Variable: Immediate Post-test } \\
\hline Source & $\begin{array}{l}\text { Type III } \\
\text { Squares }\end{array}$ & df & Mean Square & $\mathrm{F}$ & Sig. & $\begin{array}{l}\text { Partial } \\
\text { Squared }\end{array}$ & Eta \\
\hline Corrected Model & $234.173^{\mathrm{a}}$ & 2 & 117.086 & 36.493 & .000 & .730 & \\
\hline Intercept & 221.489 & 1 & 221.489 & 69.034 & .000 & .719 & \\
\hline Pre-test & 20.839 & 1 & 20.839 & 6.495 & .017 & .194 & \\
\hline Instruction & 174.538 & 1 & 174.538 & 54.400 & .000 & .668 & \\
\hline Error & 86.627 & 27 & 3.208 & & & & \\
\hline Total & 2644.000 & 30 & & & & & \\
\hline Corrected Total & 320.800 & 29 & & & & & \\
\hline
\end{tabular}


As depicted in Table 6, there was a significant difference between the post-test scores due to the effect of treatment type, $\mathrm{F}(1,29)=54.4, p=.00$, partial eta squared $=0.66$. In other words, about 66 percent of the difference between two groups can be attributed to the role of intervention type. However, the effect of difference in pre-test scores on the immediate post-test performance was also significant, $\mathrm{F}(1,29)=6.49, p=.00$, partial eta squared $=0.19$. That is, only 19 percent of the difference can be explained by the differences in pre-test scores. To remove the effect of covariate on the immediate post-test scores, estimated marginal means were taken into account.

Table 7. Estimated marginal means

\begin{tabular}{|c|c|c|c|c|}
\hline \multicolumn{5}{|c|}{ Dependent Variable: Immediate Post-test } \\
\hline \multirow[t]{2}{*}{ Instruction } & \multirow[t]{2}{*}{ Mean } & \multirow[t]{2}{*}{ Std. Error } & \multicolumn{2}{|c|}{$95 \%$ Confidence Interval } \\
\hline & & & Lower Bound & Upper Bound \\
\hline Peer-DA & $11.275^{\mathrm{a}}$ & .469 & 10.314 & 12.236 \\
\hline Non-Peer-DA & $6.325^{\mathrm{a}}$ & .469 & 5.364 & 7.286 \\
\hline
\end{tabular}

a. Covariates appearing in the model are evaluated at the following values: pre-test $=3.70$.

After adjusting for the pre-test scores, a significant difference between Peer-DA and Non-Peer-DA groups, 0.54, in terms of gains in grammar was revealed, $\mathrm{F}(1,29)=54.4, p=.00$, partial eta squared $=0.66$. Thus, it can be said that the two groups performed differently after receiving two different instructions.

The second research question investigated whether there was a significant difference between the experimental and control groups' long-term retention of grammar points. First, like the previous question, Leven's test of the equality of the variances revealed that the variability of scores for the experimental and control groups was similar. As observed in Table 8, the sig level (0.08) was larger than alpha level (0.05), meaning that the assumption of the equality of the variance has been met. To answer the second question, therefore, like the previous question, a parametric data analysis technique, one-way ANCOVA, was employed.

Table 8. Leven's test of equality of error variance

Dependent Variable: Delayed Post-test

$\begin{array}{lllr}\text { F } & \text { df1 } & \text { df2 } & \text { Sig. } \\ 3.178 & 1 & 28 & .085\end{array}$

Tests the null hypothesis that the error variance of the dependent variable is equal across groups.

a. Design: Intercept + pre-test + Instruction

The descriptive statistics reported in Table 9 displayed that there was a difference of means (peer-DA, M = 11.53, SD = 2.23; non-Peer-DA, $\mathrm{M}=5.46, \mathrm{SD}=1.55$ ) between the delayed post-test scores of two groups; to see, thus, whether the difference was significant and how much of the difference was due to the influence of intervention type, One-way ANOVA was used. 
Table 9. Descriptive statistics for comparing the Peer-DA and Non-Peer-DA on the delayed post-tests

$\begin{array}{llll}\text { Dependent Variable: Delayed Post-test } & \\ \text { Instruction } & \text { Mean } & \text { Std. Deviation } & \mathrm{N} \\ \text { Peer-DA } & 11.5333 & 2.23180 & 15 \\ \text { Non-Peer-DA } & 5.4667 & 1.55226 & 15 \\ \text { Total } & 8.5000 & 3.61749 & 30\end{array}$

Table 10. One-way ANCOVA test for comparing the Peer-DA and Non-Peer-DA on the delayed post-test

\begin{tabular}{|c|c|c|c|c|c|c|}
\hline \multicolumn{7}{|c|}{ Tests of Between-Subjects Effects } \\
\hline \multicolumn{7}{|c|}{ Dependent Variable: Delayed Post-test } \\
\hline Source & $\begin{array}{l}\text { Type III Sum of } \\
\text { Squares }\end{array}$ & df & Mean Square & $\mathrm{F}$ & Sig. & Partial Eta Squared \\
\hline Corrected & $307.687^{\mathrm{a}}$ & 2 & 153.843 & 57.841 & .000 & .811 \\
\hline \multicolumn{7}{|l|}{ Model } \\
\hline Intercept & 175.768 & 1 & 175.768 & 66.084 & .000 & .710 \\
\hline Pre-test & 31.653 & 1 & 31.653 & 11.901 & .002 & .306 \\
\hline Instruction & 222.926 & 1 & 222.926 & 83.814 & .000 & .756 \\
\hline Error & 71.813 & 27 & 2.660 & & & \\
\hline Total & 2547.000 & 30 & & & & \\
\hline Corrected Total & 379.500 & 29 & & & & \\
\hline
\end{tabular}

a. R Squared $=.811$ (Adjusted R Squared $=.797$ )

As shown in Table 10, there was a significant difference between the delayed post-test scores of the groups due to the effect of treatment type, $\mathrm{F}(1,29)=83.8, \mathrm{P}=.00$, partial eta squared $=0.75$. In other words, about 75 percent of the differences can be attributed to the role of intervention type, Peer-DA and non-Peer-DA. However, the effect of difference in the post-test scores on the delayed post-test performance was also significant, $\mathrm{F}(1,29)=31.6, \mathrm{P}=.00$, partial eta squared $=0.30$. That is, only 30 percent of the difference can be explained by the differences in the posttest scores. To remove the effect of covariate on the immediate post-test scores, estimated marginal means were taken into account (Table 11).

Table 11. Estimated marginal means

\begin{tabular}{|c|c|c|c|c|}
\hline Estimates & & & & \\
\hline Dependent Va & Delayed & & & \\
\hline Instruction & Mean & Std. Error & $95 \%$ Confiden & \\
\hline & & & Lower Bound & Upper Bounc \\
\hline Peer-DA & $11.297^{\mathrm{a}}$ & .427 & 10.422 & 12.172 \\
\hline Non-Peer-DA & $5.703^{\mathrm{a}}$ & .427 & 4.828 & 6.578 \\
\hline
\end{tabular}

a. Covariates appearing in the model are evaluated at the following values: pre-test $=3.70$. 
After adjusting for post-test scores, a significant difference between Peer-DA and non-Peer-DA groups, 0.83 , in terms of gains in grammar was revealed, $\mathrm{F}(1,29)=83.8, \mathrm{P}=.00$, partial eta squared $=0.75$.

\section{Discussion}

As outlined above, Vygotsky (1978) argued against the general and dominant view that the aim of assessment and testing should be to measure student' current knowledge or abilities. Instead, he suggested that if assessment wants to get the target aims, it should deal with explaining the basic causes of learners' performance. In this regard, the DA approaches to language teaching, conceptually rooted in ZPD, was introduced and supported in contrast to non-DA. However, one of the demerits of DA, according to language practitioners, is that it is too time-consuming and is not applicable in crowded L2 classrooms. In order to overcome this problem, alternative approaches including G-DA (Poehner, 2009), C-DA (Poehner \& Lantolf, 2013), and Peer-DA (Rezaee, Miri \& Razavipour, 2015) have been introduced. Therefore, the current study probed into the effect of the Peer-DA approach on grammar learning in intermediate EFL learners.

In accordance with the aims of the study, the first research question investigated whether Peer-DA leads to any significant improvement in the grammar learning of intermediate EFL learners. The analyses of the obtained data revealed that there was a statistically significant difference between the experimental and control groups in the posttest phase in terms of grammar learning. In actuality, the findings revealed that Peer-DA group outperformed non-DA group in learning the target structures. The results may suggest that the offered mediations sensitive to the participants' ZPD by their peers in a collaborative setting could lead to substantial changes in their grammatical learning. It is worth noting that this is in harmony with the theoretical foundations upon which DA is built. This significant improvement in learning grammatical knowledge indicates that when the offered mediation is attuned to the learners' ZPD, it can, as Haywood and Lidz (2007) put it, bring to the surface the abilities that have completely developed along with those which are on the verge of developing and emerging enabling the mediator to provide opportunities for the development of new abilities. More importantly, the findings indicated that Peer-DA approach when it is applied appropriately could diagnose and promote grammatical knowledge that is in line with the previous results reported by Ableeva and Lantolf (2011). Their study proved improvement in listening ability as measured by an increase in the number of idea units recalled over time and as a result of offering appropriate mediation. It also showed that learners were able not only to diagnose and improve the learning problems but also to transfer their ability, to some extent, to more complex texts.

To put it briefly, the results can be ascribed to the fact that members of Peer-DA group could pool their resources together so as to scaffold each other to acquire the structures effectively. In fact, the Peer-DA students managed to shape ZPDs and assist each other to go forward within these newly co-constructed ZPDs. Simply put, they jointly cobuilt what they were unable to carry out individually and later on internalized the co-shaped knowledge and transfer it to future individual performance. It was observed that parties to each group were sensitive to their teammates' needs. They provided adequate feedback whenever needed and withdrew it the time the need was removed. Thus, it can be claimed that this continuous provision of ZPD-sensitive feedback assisted parties to each group to go beyond their current level of individual abilities. In Vygotskian (1978) terms, what was co-constructed at inter-psychological level (among the group members) was successfully internalized for later use at intra-psychological level (inside individual's mind).

The positive impact of the treatment can be further espoused by the concepts of primary and secondary interactants as explained by Poehner (2009). Poehner notes that an engagement with the entire group should be taken to mean ignoring mediation to individuals. Rather, every mediating move should target the group as well. Seen from this perspective, it is notable that whenever the learners, being primary interactant in one feedback episode and secondary in another one, were addressed by the mediator and engaged in ZPD-sensitive feedback, they were prompted to do what they were individually unable to do and then they could appropriate the co-formed knowledge and awareness. In fact, according to van Compernolle and Williams (2013), the unaddressed students could use the graduated feedback since they could function as active recipients; the secondary participants may play a role in the ZPD-sensitive dialogic discussions by embodied participation (e.g., eye-movement and head turning) or private speech (e.g., vicarious response and repeating some contributions). Further, engagement in ZPD-sensitive feedback may be mutually beneficial for both addressed (primary interactants) and unaddressed (secondary interactants) because it prompts them notice gaps in their interlanguage regarding the target structures. 
The findings of the study could lend support to the study carried out by Kozulin and Grab (2002). The results of their study indicated that many of the participants benefited from the mediation and were able to apply the acquired strategies to the new text. They, also, found that the students with identical pre-test acted differently at the post-test. These findings confirmed the practical value the dynamic procedure applied in that it provided the researchers with in-depth information about the different learning needs of students having the same standard performance scores. In addition, the results of the study are in accordance with Ableeva and Lantolf's (2011) research. They presented and discussed quantitative recall data from a longitudinal study that investigated the effects of DA on diagnosing and promoting listening comprehension in French as a second language. Their study proved improvement in listening ability as measured by an increase in the number of idea units recalled over time and as a result of mediation.

The second research question examined whether the Peer-DA teaching can lead to any significant improvements in EFL learners' long-term retention in grammar learning. The answer to this question was positive as well. As the analysis of the collected data revealed, there existed a statistically significant difference between the experimental and control groups on the delayed post-test regarding the ability to recall the grammatical structures after three weeks. These findings may propose that Peer-DA, when employed properly, may have an effective impact on improving language learners' grammar learning in terms of long retention. The findings of the study indicated that not only can Peer-DA have the potentiality to diagnose the learners' difficulties but it also may enhance them much efficiently so that the students can recall them with ease later. That is to say, when the students were working collaboratively on the structures, they were able to diagnose each other's problems and remove them by using the procedures of Peer-DA. For example, when a misunderstanding raised, the students somehow rectified it by offering contingent and gradual prompts for their peers. This finding lends support to the results obtained by Rezaee, Miri, and Ravaipour (2015) where they found that Peer-DA can improve vocabulary and reading comprehension of EFL learners.

Moreover, the findings of the current study are in harmony with Davin and Donato (2013). They set out to explore the contribution of small-group collaborative tasks as a complement to classroom DA in a primary school language classroom. The authors believe that one way to have all students of a class benefit from DA principles is to add small group collaborative tasks to classes. So, having run five days of a class of young language learners based on DA principles which aimed to teach WH-question formation, Davin and Donato (2013) got the students to work in small groups on a collaborative writing task. Findings revealed that students drew upon collective knowledge to complete the task. Also, characteristics such as repetition and first language usage appeared in peer scaffolding though they were different from the DA mediation the teacher provided during the first phase of the study. That is, the students could not appropriate DA-based forms of mediation and apply them in their peer collaborative tasks. In corresponding with the obtained results of the current research, it can be concluded that when the different learners with different ZPDs engaged in learning grammatical structures, all learners may benefit from receiving provided mediations.

\section{Conclusion}

The current study probed into the applicability of P-DA approach for teaching grammar in Iranian EFL context. As discussed earlier, Vygotsky (1998) argued against the dominant view that the purpose of assessment should be to measure individuals' developed knowledge or abilities. Instead, his suggestion was that instruction and assessment should be concerned with explaining the underlying causes of an individual's performance and they should target the developing abilities. Of course, it should be noted that in order to achieve these aims, as was shown above, the mediations should be provided in a contingent, graduated, and interactive way so that not only can the learners find out the location of the difficulties and problems but also they can correct them confidently.

Taken together, the findings may serve as evidence for this idea that DA and its alternative approaches such as PeerDA cannot totally substitute non-DA. They can be employed as a useful complement for non-DA approaches in testing. We can get to deeper insights and much better results regarding the ultimate achievement of EFL learners if we employ Peer-DA approach even with standardized test instruments. This can bring lots of advantages to language teachers and students using Peer-DA can provide valuable information for instructional programming. Finally and more importantly, the results provide evidence supporting the applicability of Peer-DA approach in crowded classes.

Based on the obtained findings, some pedagogical implications can be raised. One of the important implications is that Peer-DA should be taken into account as an alternative approach to non-DA. Precisely speaking, both Peer-DA and non-DA should be employed hand in hand in EFL education since they can complement each other in an efficient way. Another implication of the present study can be justified with this complementary nature of DA procedures. At best, the obtained findings reject the view that those L2 learners who are not able to perform a task independently are 
not cognitively disabled and they should not be frowned upon. Instead, by providing tailored treatments for learners our teaching turns out to be more successful. The results of the study are especially useful for those teachers who have underachievers in their classes. In this situation, language teachers can assign both overachiever and underachiever students in the same group to use Peer-DA procedures to assist each other. Finally, in line with the findings it can be recommended that mediations offered by peers should address the needs and preferences of students and take into account learners' individual differences.

Although the findings of the current study could, to some extent, provide supportive evidence on the effectiveness of Peer-DA on grammar learning among Iranian EFL learners, there existed some limitations that should be taken into account. First, the sampling method was non-random and the selected participants were just female gender. This may jeopardize the generalizability of the findings. Further, the group sizes were small, as a result of which statistical analyses may lose force; thus, future attempts might apply larger samples and recruit both genders. In addition, the study was carried out at a private school context and the effect of Peer-DA on other situations may beg for further investigations. Finally, the present research probed into specifically grammar learning, there are other areas of language components and language skills which are in need of further research.

\section{References}

Ableeva, R., \& Lantolf, J. P. (2011). Mediated dialogue and the microgenesis of second language listening comprehension. Assessment in education: Principles, policy and practice, 1(8), 133-149. https://doi.org/10.1080/0969594X.2011.555330.

Aljaafreh, A., \& Lantolf, J. P. (1994). Negative feedback as regulation and second language learning in the zone of proximal development. Modern Language Journal, 7(8), 465-483. https://doi.org/10.1111/j.15404781.1994.tb02064.x.

Birjandi, P., Estaji, M., \& Deyhim, T. (2013). The impact of dynamic assessment on reading comprehension and metacognitive awareness of reading strategy use in Iranian high school learners. Iranian Journal of Language Testing, 3(2), 60-77. https://pdfs.semanticscholar.org.

Carney, J. J., \& Cioffi, G. (1992). The dynamic assessment of reading abilities. International Journal of Disability Development and Education, 39(2), 107-114. https://doi.org/10.1080/0156655920390203.

Davin, K. J. (2011). Group dynamic assessment in an early foreign language learning program: Tracking movement through the zone of proximal development. Unpublished Ph.D. dissertation, the University of Pittsburgh, Pittsburgh, PA.

Davin, K. J. (2013). Integration of dynamic assessment and instructional conversational to promote development and improve assessment in the language classroom. Language Teaching Research, 17(3), 303-323. https://doi.org/10.1177\%2F1362168813482934.

Davin, K. J., \& Donato, R. (2013). Student collaboration and teacher-directed classroom dynamic assessment: a complementary pairing. Foreign Language Annals, 4(6), 5-22. https://doi.org/10.1111/flan.12012.

Ellis, R. (2008). The study of second language acquisition. (2nd ed). Oxford: Oxford University Press.

Embretson, E. S. (2004). The second century of ability testing: Some predictions and speculations. Measurement and $\begin{array}{llll}\text { Interdisciplinary Research and Perspectives, } & \text { 2(1), }\end{array}$ https://psycnet.apa.org/doi/10.1207/s15366359mea0201_1.

Freeman, L. D. (2014). Teaching grammar. In M. Celce Murcia (Eds.), Teaching English as a second or foreign language (pp. 256-270). Boston, M.A.: Heinle and Heinle.

Haywood, H. C., \& Lidz, C. S. (2007). Dynamic assessment in practice: Clinical and educational applications. Cambridge: Cambridge University Press.

Khoshsima, H., \& Rezaee, A. (2016). Applicability of peer-dynamic assessment in crowded second language classes. Journal of Language Teaching and Research, 7(5), 929-935. http://dx.doi.org/10.17507/jltr.0705.13

Kozulin, A., \& Garb, E. (2002). Dynamic assessment of EFL text comprehension. School Psychology International, 23(1), 112-127. https://doi.org/10.1177/0143034302023001733 
Krashen, S. (1982). Principle and practice in second language acquisition. Oxford: Pergamum.

Lantolf, J. P., \& Peohner, M. E. (2014). Sociocultural theory and the pedagogical imperative in L2 education. London and New York: Rutledge

Lantolf, J. P., \& Thorne, S. L. (2006). Sociocultural theory and the genesis of second language development. Oxford: Oxford University Press.

Lidz, C. S., \& Gindis, B. (2003). Dynamic assessment of the evolving cognitive functions inchildren. In A. E. Kozulin, J. S. Brown, S. M. Miller, C. Heath, B. Gindis, \& V. S. Ageyev (Eds.), Vygotsky's educational theory in cultural context (pp. 99-116). Cambridge, UK: Cambridge University Press.

Lightbown, P. M., \& Spada, N. (2013). How languages are learned? ( $3^{\text {rd }}$ ed). Oxford: Oxford University Press.

McNamara, T. F. (2001). Language assessment as social practice: Challenges for research language testing. Oxford: Oxford University Press.

Poehner, M. E. (2008). Dynamic assessment: A Vygotskyan approach to understanding promoting second language development. Berline: Springer.

Poehner, M. E. (2009). Group dynamic assessment: Mediation for the L2 classroom. TESOL Quarterly, 43(3), 471491. https://doi.org/10.1002/j.1545-7249.2009.tb00245.x

Poehner, M. E., \& Lantolf, J. P. (2005). Dynamic assessment in the language classroom. Language Teaching Research, 9(1), 1-33. https://doi.org/10.1191/13621688051r166oa

Poehner, M. E., \& Lantolf, J. P. (2013). Bringing the ZPD into the equation: Capturing L2 development during computerized dynamic assessment. Language Teaching Research, 17(3), 323-342. https://doi.org/10.1177\%2F1362168813482935.

Rezaee, A., Miri, M., \& Razavipour, K. (2015). Effects of informed peer-dynamic assessment on reading comprehension and vocabulary learning. Journal of Research in Applied Linguistics (special issue), 319-328.

Tabatabee, M., Alidoust, M., \& Sarkeshikian, A. (2018). The effect of interventionist and cumulative group dynamic assessments on EFL learners' writing accuracy. Applied Linguistics Research Journal, 2(1), 1-13.

van Compernolle, R. A., \& Williams, L. (2013). Promoting sociolinguistic competence in the classroom zone of proximal development. Language Teaching Research, 16(1), 39-60. https://doi.org/10.1177\%2F1362168811423340.

Vygotsky, L. S. (1978). Mind in society: The development of higher psychological processes. Cambridge, MA: Harvard University Press. 